\title{
Erratum to: Hydrophobic Interaction Between Domain I of Albumin and B Chain of Detemir May Support Myristate-Dependent Detemir-Albumin Binding
}

\author{
Sadaf Fatima ${ }^{1} \cdot$ Priyankar Sen $^{2} \cdot$ P. Sneha ${ }^{3}$. \\ C. George Priyadoss ${ }^{3}$
}

Published online: 2 December 2016

(C) Springer Science+Business Media New York 2016

Erratum to: Appl Biochem Biotechnol (2016)

DOI: 10.1007/s12010-016-2312-4

Unfortunately, there's an error in one of the author's name in the original publication of the article. C. George Priyadoss was incorrectly captured as C. George Priya Doss. The original article was corrected.

The online version of the original article can be found at http:10.1007/s12010-016-2312-4.

Sadaf Fatima

sfatima1@jmi.ac.in

Priyankar Sen

priyankar.sen@vit.ac.in

C. George Priyadoss

georgepriyadoss@vit.ac.in

1 Genes and Proteins Lab, Department of Biotechnology, Jamia Millia Islamia, New Delhi 110025, India

2 Centre for Bioseparation Technology, VIT University, Vellore 632014, India

3 Department of Integrative Biology, School of Bio Sciences and Technology, VIT University, Vellore 632014, India 